SHORT REPORT

\title{
Polymicrobial candidaemia revealed by peripheral blood smear and chromogenic medium
}

H Yera, D Poulain, A Lefebvre, D Camus, B Sendid

J Clin Pathol 2004;57:196-198. doi: 10.1136/icp.2003.9340

Candida spp are the fourth most common group of nosocomial pathogens isolated from patients on medical, surgical, and intensive care wards. Polymicrobial candidaemia has rarely been described. The diagnosis of candidaemia from peripheral blood smears has not been widely reported. This report describes the case of a young woman suffering from Ewing's sarcoma who developed a syndrome of septic shock. Deep fungal infection was diagnosed from a systematic peripheral blood smear and yeasts were isolated within 24 hours. A subculture on CHROMagar ${ }^{\circledR}$ Candida allowed the differentiation and presumptive identification of Candida tropicalis and Candida krusei. Species identification was confirmed by the ID $32 C^{\circledR}$ system. This report underlines the usefulness of peripheral blood smears in the diagnosis of fulminant deep fungal infections, and of a differential isolation medium in the rapid presumptive identification of clinically important yeast species from clinical samples. This medium is particularly useful for the detection of mixed fungal infections, allowing early and better adapted antifungal treatment.

F ungal pathogens, in particular Candida spp, have become a major cause of nosocomial infection. ${ }^{12}$ An epidemiological study conducted in four Swiss university hospitals showed that Candida spp were the fourth most common microorganisms isolated from patients on medical, surgical, and intensive care wards. ${ }^{3}$ Predisposing factors for disseminated candidiasis include immunosuppressive chemotherapy, indwelling catheters, multiple antibiotic treatment, and heart or abdominal surgery. Mortality rates for systemic candidiasis are high, ranging from $50 \%$ to $80 \%$, despite appropriate treatment. $^{2}$

Because clinical signs are non-specific, the diagnosis of systemic candidiasis remains difficult. ${ }^{4}$ Diagnosis is currently based on the isolation of Candida spp from normally sterile sites, but such methods lack sensitivity. ${ }^{5}$ Many efforts have been made to develop more sensitive approaches. Among these, recent studies have reported that the detection of circulating candida mannan and anti-mannan antibodies has improved sensitivity for the detection of infectious episodes caused by the most pathogenic species of candida. ${ }^{67}$ The use of molecular diagnostic tools to detect candida nucleic acid sequences has promised both high detection rates and the identification of specific species. ${ }^{7}$ Pittet and co-workers proposed the determination of a candida colonisation index to identify patients at high risk of developing deep candida infection. ${ }^{8}$ However, a general consensus has not been reached on the usefulness of any of these methods, and no specific method is currently recommended by physicians, except for blood culture and histological examination.
Previous reports have suggested that peripheral blood smears may be useful for the detection of disseminated yeast infection (table 1). The yeast species detected to date in peripheral blood smears include Histoplasma capsulatum, Cryptococcus neoformans, Candida spp, Hansenula anomala, Penicillium marneffei, and Rhodotorula spp.

\section{"Because clinical signs are non-specific, the diagnosis of} systemic candidiasis remains difficult"

Polymicrobial candidaemia has been described infrequently. ${ }^{9}$ However, the isolation and identification methods used routinely could miss mixed yeast cultures. ${ }^{10}$ Several cases of mixed species candidaemia were detected using a differential isolation medium containing chromogenic substrates, CHROMagar ${ }^{\circledR}$ Candida, ${ }^{11}$ and polymerase chain reaction methods, whereas conventional methods identified a single causative species.

Our report describes the detection of a disseminated coinfection with Candida tropicalis and Candida krusei in a peripheral blood smear, which was confirmed with CHROMagar Candida, and the speciation of isolates by biochemical tests.

\section{CASE REPORT}

A 16 year old girl had a clinical history of Ewing's sarcoma localised on the right femur with medullary metastases (D4 to D6) diagnosed in February 1999. She was treated with five courses of chemotherapy (adriamycin/cyclophosphamide), followed in July by two further courses of mephalan/busulfan, and autologous peripheral blood stem cell transfusion.

At the beginning of September, the patient developed Lyell's syndrome after administration of cotrimoxazole. She was transferred to the paediatric intensive care unit where her condition worsened and cutaneous lesions, which were infected by Staphylococcus spp, spread widely. She developed a vein occlusive disease with hepatomegaly, splenomegaly, and major hepatic cytolysis, ascites, and cholostase. She also presented with acute renal insufficiency. Septic shock appeared on 15 September and she died less than 24 hours later, despite the introduction of antifungal treatment with liposomal amphotericin B (Ambisome ${ }^{\circledR} ; 5 \mathrm{mg} / \mathrm{kg} /$ day intravenously).

A white blood cell count performed on 9 September revealed 14300 cells $/ \mathrm{mm}^{3}$, mostly polymorphonuclear neutrophils $(73 \%)$. Six days later, on 15 September, the white blood cell count was 35500 cells $/ \mathrm{mm}^{3}$, with $60 \%$ polymorphonuclear neutrophils, $1 \%$ metamyelocytes, and $3 \%$ myelocytes. On May-Grumwald-Giemsa stained smears, polymorphonuclear neutrophil cells were damaged morphologically, and showed vacuolisation and intracytoplasmic yeast cells (fig 1). The yeast cells were both intracellular and extracellular, and consisted of round or oval blastospores and pseudohyphae. Blood cultures were carried out immediately 
Table 1 Review of clinical cases of disseminated yeast infection diagnosed from peripheral blood smears

\begin{tabular}{|c|c|c|c|c|c|}
\hline Ref & $\begin{array}{l}\text { No. of } \\
\text { cases }\end{array}$ & Category of patients & Outcome & Isolated species & $\begin{array}{l}\text { Antifungal } \\
\text { treatment }\end{array}$ \\
\hline Berrouane et al. J Clin Pathol 1998;51:537-8 & 1 & Intestinal obstruction & Death & Candida albicans & Fluconazole \\
\hline \multirow[t]{2}{*}{ Manabe et al. Rinsho Ketsueki 1997;38:669-73 } & 1 & Disseminated neuroblastoma & Death & Rhodotorula rubra & - \\
\hline & 1 & Langerhan's cell histiocytosis & Death & Candida guilliermondii & $\mathrm{AMB}$ \\
\hline Gavinet et al. J Mycol Med 1995;5:53-5 & 1 & Epidermoidal carcinoma & Death & Candida glabrata & $\mathrm{AMB}$ \\
\hline \multirow{2}{*}{$\begin{array}{l}\text { Chao et al. Bone Marrow Transplant } \\
1994 ; 14: 647-9\end{array}$} & 1 & Syngeneic BMT & Alive & Candida parapsilosis & Fluconazole \\
\hline & 1 & Allogeneic BMT & Alive & Rhodotorula glutinis & $A M B$ \\
\hline $\begin{array}{l}\text { Girmenia and Jaalouk. Eur J Haematol } \\
1994 ; 52: 124-5\end{array}$ & 4 & Haematological malignancies & Alive & $\begin{array}{l}\text { C parapsilosis (2), } \\
\text { C guilliermondii (1), } \\
\text { Hansenula anomala (1) }\end{array}$ & - \\
\hline $\begin{array}{l}\text { Supparatpinyo and Sirisantana. Clin Infect Dis } \\
1994 ; 18: 246-7\end{array}$ & 1 & AIDS & Loss of sight & Penicillium marneffei & $A M B$ \\
\hline $\begin{array}{l}\text { Casanova-Cardiel and Ruiz-Ordaz. Rev Invest Clin } \\
\text { 1993;45:67-70 }\end{array}$ & 4 & AIDS & Death & Histoplasma capsulatum & $\begin{array}{l}\text { None (1), AMB } \\
\text { (3) }\end{array}$ \\
\hline \multirow[t]{3}{*}{ Marshall et al. Am J Clin Pathol 1990;93:526-32 } & 2 & AIDS & - & H capsulatum (2) & - \\
\hline & 2 & Prematurity & - & $\begin{array}{l}\text { Calbicans (1), } \\
\text { C parapsilosis (1) }\end{array}$ & - \\
\hline & 2 & Intestinal diseases & - & $\begin{array}{l}\text { Calbicans (1), Candida } \\
\text { tropicalis (1) }\end{array}$ & - \\
\hline Rosti et al. Haematologica 1990;75:480-1 & 1 & Allogeneic BMT & Alive & C tropicalis & Liposomal AMB \\
\hline Yao et al. Am J Med 1990;89:100-2 & 1 & AIDS & Death & Cryptococcus neoformans & - \\
\hline Buchman et al. JAMA 1988;260:2926 & 1 & Longterm total parenteral nutrition & Alive & C glabrata & $A M B$ \\
\hline Kates et al. Lab Med 1988;19:25 & 1 & Longterm total parenteral nutrition & Alive & $\begin{array}{l}\text { Candida krusei, then C } \\
\text { albicans }\end{array}$ & $\mathrm{AMB}$ \\
\hline Ossenkoppele et al. Neth J Med 1988;33:30-2 & 1 & Autologous BMT & Alive & C parapsilosis & $\mathrm{AMB}$ \\
\hline $\begin{array}{l}\text { Dietriech et al. Schweiz Med Wochenschr } \\
\text { 1987;117:1289-96 }\end{array}$ & 1 & AIDS & Death & $H$ capsulatum & - \\
\hline $\begin{array}{l}\text { Monihan et al. Arch Pathol Lab Med } \\
\text { 1986;110:1180-1 }\end{array}$ & 1 & CLL and Kaposi's sarcoma & Death & C parapsilosis & $\mathrm{AMB}$ \\
\hline Paul et al. Pediatr Infect Dis 1986;5:274-5 & 1 & AIDS & Death & H capsulatum & $\mathrm{AMB}$ \\
\hline Baptist et al. N Y State J Med 1985;85:664-5 & 1 & AIDS & Death & $H$ capsulatum & None \\
\hline Henochowicz et al. JAMA 1985;253:3148 & 1 & AIDS & Death & $H$ capsulatum & $A M B$ \\
\hline Macher et al. Ophthalmology 1985;92:1159-64 & 1 & AIDS & Death & H capsulatum & $A M B$ \\
\hline Wheat et al. Am J Med 1985;78:203-10 & 1 & AIDS & Death & H capsulatum & $A M B$ \\
\hline Bonner et al. Arch Intern Med 1984;144:2178-81 & 1 & AIDS & Alive & $H$ capsulatum & $A M B$ \\
\hline \multirow{2}{*}{ Girard et al. South Med J 1977;70:65-6 } & 1 & Metastatic carcinoma & Death & $H$ capsulatum & $\mathrm{AMB}$ \\
\hline & 1 & Hodgkin lymphoma & Death & $H$ capsulatum & $\mathrm{AMB}$ \\
\hline Kobza and Steenblock. BMJ 1977;1:1640-1 & 1 & Intestinal obstruction & Alive & Calbicans & $\mathrm{AMB}+5 \mathrm{FC}$ \\
\hline \multirow[t]{2}{*}{ Portnoy et al. N Engl J Med 1971;285:1010-11 } & 1 & Intestinal obstruction & Alive & C albicans & $\mathrm{AMB}+5 \mathrm{FC}$ \\
\hline & 1 & Malabsorption syndrome & Death & Calbicans & $\mathrm{AMB}$ \\
\hline Hahn et al. MO Med 1973;70:249-50 & 1 & $\mathrm{CLL}$ & Death & H capsulatum & $A M B$ \\
\hline Silverman et al. Am J Clin Pathol 1973;60:473-5 & 1 & Intestinal obstruction & Death & Calbicans & $A M B$ \\
\hline Jacobs. JAMA 1969;207:1916 & 1 & Renal transplantation & Death & H capsulatum & - \\
\hline $\begin{array}{l}\text { Lopez and Grocott. Am J Clin Pathol } \\
\text { 1968;50:692-4 }\end{array}$ & 1 & Histiocytosis X & Death & $H$ capsulatum & $A M B$ \\
\hline $\begin{array}{l}\text { Holland and Holland. Am J Dis Child } \\
1966 ; 112: 412-21\end{array}$ & 1 & Abdominal distension & Death & H capsulatum & $A M B$ \\
\hline $\begin{array}{l}\text { Jobe and Koepke. Tech Bull Regist Med Technol } \\
\text { 1966;36:156-7 }\end{array}$ & 1 & Anaemia & Death & $H$ capsulatum & $\mathrm{AMB}$ \\
\hline Hood et al. Can Med Assoc J 1965;93:587-92 & 1 & Renal homotransplantation & Death & H capsulatum & - \\
\hline Silverman et al. Am J Med 1955;19:410-59 & 1 & - & Death & $H$ capsulatum & - \\
\hline $\begin{array}{l}\text { Ffrench and Shemoi. Can Med Assoc J } \\
1954 ; 71: 238-41\end{array}$ & 1 & Aplastic anaemia & Death & Calbicans & - \\
\hline $\begin{array}{l}\text { Parsons and Zarafonetis. Arch Intern Med } \\
\text { 1945;75:1-23 }\end{array}$ & 1 & - & Death & $H$ capsulatum & - \\
\hline Reid et al. J Lab Clin Med 1942;27:419-34 & 1 & - & Death & H capsulatum & - \\
\hline Amolsch and Wax. Am J Pathol 1939;15:477-81 & 1 & - & Death & H capsulatum & - \\
\hline $\begin{array}{l}\text { Dodd and Tompkins. Am J Trop Med } \\
\text { 1934;14:127-37 }\end{array}$ & 1 & Anaemia & Death & $H$ capsulatum & - \\
\hline
\end{tabular}

on Bactec $^{\circledR} 9050$ mycosis aerobic medium and yeasts were isolated 24 hours later. Identification of the yeasts was performed using the following standard tests: BICHRO LATEX ALBICANS ${ }^{\circledR}$, which was negative, and the ID $32 \mathrm{C}^{\circledR}$ system, which was uninterpretable, suggesting the possibility of a mixed yeast infection. A subculture on CHROMagar Candida revealed two types of colony: $C$ tropicalis (blue with a halo) and $C$ krusei (pink). This presumptive identification was confirmed with the ID 32C system.

\section{DISCUSSION}

In most reported cases, the observation of fungal elements in peripheral blood smears from patients has allowed an early diagnosis and the initiation of antifungal treatment (table 1). The diagnosis was mainly fortuitous in systematic peripheral blood smears stained with May-Grumwald-Giemsa or Giemsa, often when performing a white blood cell count. Most patients described had haematological malignancies, AIDS, or intestinal obstruction, and the fungaemias in these patients were associated with a high mortality rate $(62 \%)$. Histoplasma capsulatum was involved in 26 of the 52 reported cases of disseminated yeast infection. Among these, 13 cases were in patients with AIDS. The second most common cause of fungaemia was Candida spp. Most episodes were seen in patients with haematological malignancies (eight of 14) or intestinal diseases (seven of eight). Candida albicans was involved in six of the seven cases of disseminated candidiasis 

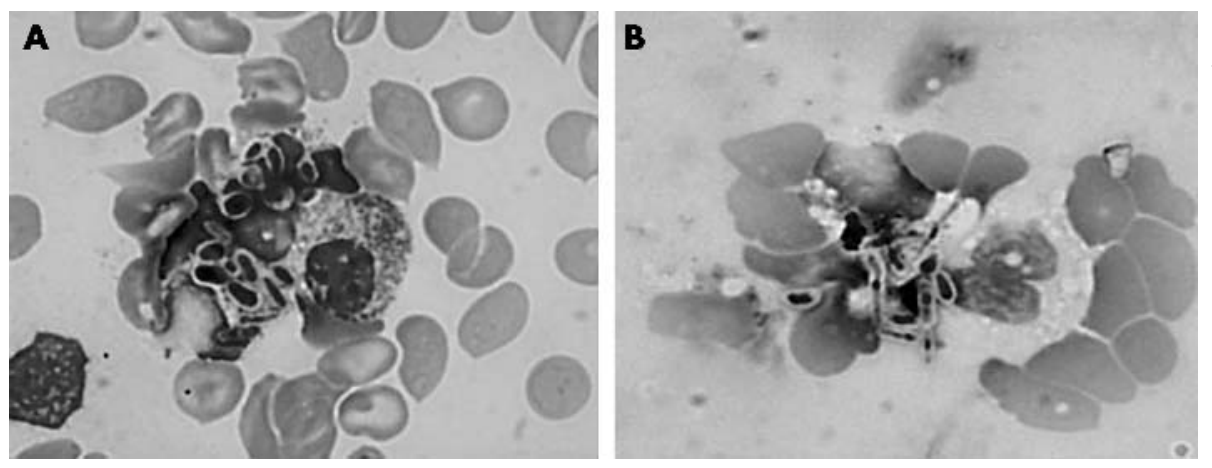

Figure 1 Peripheral blood smear with yeast blastoconidia and pseudohyphae in the cytoplasm of morphopolynuclear cells (May-Grumwald-Giemsa stain; original magnification, $\times 1000$ )

\section{Take home messages}

- Peripheral blood smears are extremely useful in the diagnosis of fulminant deep fungal infections

- CHROMagar ${ }^{\circledR}$ Candida isolation medium can help in the rapid presumptive identification of clinically important yeast species from clinical samples

- This medium is particularly useful for the detection of mixed fungal infections, allowing early and better adapted antifungal treatment

after severe intestinal disease. In contrast to previous reports, which mentioned only $C$ albicans in patients with a history of intestinal obstruction, our report describes a patient with similar symptoms in whom systemic infection was caused by mixed non-albicans species. On peripheral blood smears, two morphotypes of yeast were observed: round blastospores, which suggested $C$ tropicalis, and small, oval blastospores, which resembled $C$ krusei. Two distinct morphotypes could also be observed, namely: oval yeasts and pseudohyphae (fig 1). None of the other reports have described polymicrobial candidaemia, which is an infrequent clinical event. ${ }^{9}$ However, routine isolation methods could miss the detection of mixed yeast cultures. ${ }^{10}$ In broth based blood culture systems, one species might overgrow the other and prevent its detection. An agar based culture method might facilitate the detection of multiple fungal species when their colony morphologies are different. However, $C$ tropicalis and $C \mathrm{krusei}$ have similar morphotypes characterised by white to cream and butyrous colonies, with a rough texture observed for some C krusei strains. The introduction of differential isolation media might help in the detection of mixed fungal infections. ${ }^{11}$ CHROMagar Candida medium allowed the identification of two candida species in less time than conventional methods.

\section{"Routine isolation methods could miss the detection of mixed yeast cultures"}

According to statistical evaluation of CHROMagar Candida for the presumptive identification of commonly isolated yeast species, ${ }^{12}$ blue to blue/grey colonies are highly suggestive of $C$ tropicalis, whereas dry, flat, rough textured, and spreading colonies with a pale pink colour and white edges are highly suggestive of $C$ krusei. In both cases, the positive predictive value was $100 \%$. However, some strains of $C$ krusei were not identified because they produced smooth pink/purple colonies with a white edge. Thus, the systematic use of CHROMagar Candida helped not only in the presumptive identification of Candida spp, but also in detecting the presence of several yeast species in the same sample. This strategy was helpful in the initiation of appropriate antifungal treatment, which targets Candida spp according to their antifungal susceptibility. Indeed, in this patient, the $C$ krusei and $C$ tropicalis strains isolated had a different susceptibility to triazole antifungal agents, whereas most clinical isolates of $C$ krusei are resistant to fluconazole. ${ }^{13}$

\section{ACKNOWLEDGMENTS}

The authors thank N Francois for her valuable technical assistance. They are grateful to the late Dr J Fruit for her helpful advice and attention.

\section{Authors' affiliations}

H Yera, D Poulain, D Camus, B Sendid, Laboratoire de ParasitologieMycologie, Equipe Inserm E0360, CH\&U, Faculté de Médecine Pôle Recherche, Place de Verdun, 59045 Lille Cedex, France

D Poulain, B Sendid, Laboratoire de Mycologie Fondamentale et Appliquée, Equipe Inserm E0360

A Lefebvre, Centre Oscar Lambret, BP 307, 59020 Lille, France

Correspondence to: Dr B Sendid, Laboratoire de Mycologie Fondamentale et Appliquée, Equipe Inserm E0360, CH\&U, Faculté de Médecine Pôle Recherche, Place de Verdun, 59045 Lille Cedex, France; bsendid@univ-lille2.fr

Accepted for publication 28 July 2003

\section{REFERENCES}

1 Edmond MB, Wallace SE, McClish DK, et al. Nosocomial bloodstream infections in United States hospitals: a three-year analysis. Clin Infect Dis 1999;29:239-44.

2 Wenzel RP. Nosocomial candidemia: risk factors and attributable mortality. Clin Infect Dis 1995;20:1531-4.

3 Harbarth S, Ruef C, Francioli P, et al. Nosocomial infections in Swiss university hospitals: a multi-centre survey and review of the published experience. SwissNoso Network. Schweiz Med Wochenschr 1999;129:1521-8.

4 Armstrong D. Problems in management of opportunistic fungal diseases. Rev Infect Dis 1989;11(suppl 7):S1591-9.

5 Odds FC. Candida and candidiasis. In: Baillière-Tindall, ed. A review and bibliography. London, 1988:206-22

6 Sendid B, Tabouret M, Poirot JL, et al. New enzyme immunoassays for sensitive detection of circulating Candida albicans mannan and antimannan antibodies: useful combined test for diagnosis of systemic candidiasis. J Clin Microbiol 1999:37:1510-17.

7 Yeo SF, Wong B. Current status of nonculture methods for diagnosis of invasive fungal infections. Clin Microbiol Rev 2002;15:465-84.

8 Pittet D, Monod M, Suter PM, et al. Candida colonization and subsequent infections in critically ill surgical patients. Ann Surg 1994;220:751-8.

9 Pulimood S, Ganesan L, Alangaden G, et al. Polymicrobial candidemia. Diagn Microbiol Infect Dis 2002;44:353-7.

10 Shin JH, Nolte FS, Morrison CJ. Rapid identification of Candida species in blood cultures by a clinically useful PCR method. J Clin Microbiol 1997;35:1454-9.

11 Odds FC, Bernaerts R. CHROMagar Candida, a new differential isolation medium for presumptive identification of clinically important candida species. $J$ Clin Microbiol 1994;32:1923-9.

12 Powell HL, Sand CA, Rennie RP. Evaluation of CHROMagar Candida for presumptive identification of clinically important candida species. Diagn Microbiol Infect Dis 1998;32:201-4.

13 Girmenia C, Pagano L, Leone G, et al. Fluconazole and Candida kruse fungemia. Arch Intern Med 2001;161:2267-9. 